\title{
Karakter Ideal dalam Pappaseng Bugis : Implikasi Bagi Layanan Bimbingan Konseling
}

\author{
Fitriana $^{1}$, Andi Wahyu Irawan', Burhanuddin ${ }^{3}$ \\ ${ }^{1}$ Institut Agama Islam Muhammadiyah Sinjai, Sinjai \\ ${ }^{2}$ Bimbingan Konseling Universitas Mulawarman, Samarinda \\ ${ }^{3}$ Institut Agama Islam Muhammadiyah Sinjai, Sinjai \\ Korespondensi Penulis. E-mail: fitrimyrmica0789@gmail.com,Tlp:+628114616789
}

\begin{abstract}
Abstrak
Penelitian ini bertujuan untuk mengidentifikasi karakter ideal konseli dalam pappaseng Bugis dan implikasinya bagi layanan bimbingan konseling. Pappaseng Bugis dinilai memiliki nilai-nilai arif yang menjadi indikator karakter ideal manusia. Konseli atau siswa sebagai sasaran layanan dalam bimbingan konseling, merupakan pribadi yang membutuhkan bantuan dari konselor sekolah (guru bimbingan konseling). Atas dasar itu, maka perlu indikator dalam menilai karakter ideal konseli. Metode penelitian kualitatif hermeneutika Gadamerian digunakan untuk menelusuri pappaseng Bugis. Teks pappaseng Bugis dianalisis dengan menggunakan pendekatan khas hermeneutika Gadamerian. Hasil peneiltian menunjukkan bahwa Nilai-nilai dalam pappaseng Bugis yang menjadi indikator pribadi ideal adalah adalah Siri dan Pesse ( Harga Diri dan Empaty), Awaraningeng (Keberaniaan), Reso (Etos kerja), Alempureng (Kejujuran), Getteng (Keteguhan), Solidaritas, Teppe' ri Dewataeatausara' (Kepercayaan terhadap Tuhan), Abulo Sibatang (Persatuan), dan Appasitinajang (Keselarasan). Karakter ideal tersebut berimplikasi terhadap karakter ideal konseli dalam layanan bimbingan konseling, sebagaimana pandangan bahwa konseli juga adalah manusia. Nilai tersebut bisa menjadi pertimbangan dan rekomendasi dalam pelaksanaan konseling lintas budaya.
\end{abstract}

Kata Kunci: Karakter Ideal, Pappaseng Bugis, Bimbingan Konseling

\section{Pendahuluan}

Di era postmodern seperti sekarang ini, tidak bisa dipungkiri kebudayaan lama yang menjadi ciri khas disuatu daerah di Indonesia yang merupakan negara multikultural perlahan-perlahan mulai hilang. Arus globalisasi telah menjadikan masyakat Indonesia kehilangan nilai-nilailuhur karena ide-ide modernisasi telah mencengkram seiring perkembangan kehidupan. Perubahan pola pikir memandang hidup pun semakin hari semakin menjadikan moral masyarakat kehilangan jari dirinya.

Bugis adalah salah satu bagian dari budaya tersebut. Suku Bugis terletak di daerah Sulawesi Selatan. Suku Bugis adalah suku yang sangat menjunjung tinggi 


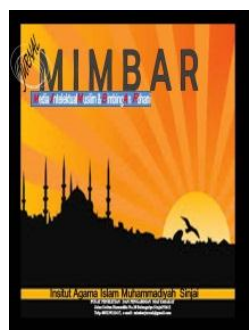

\section{MIMBAR}

Jurmal Media Intelektual Muslim dan Bimbingan Rohani

Volume 7, No. 1, 2021

ISSN (print) : 2442-3217

ISSN (online) : 2716-3806

Homepage : http://journal.iaimsinjai.ac.id/indeks.php/mimbar

harga diri dan martabat. Tidak berbeda jauh dengan suku Madura, Suku ini sangat menghindari tindakan-tindakan yang mengakibatkan turunnya harga diri atau martabat seseorang. Jika seorang anggota keluarga melakukan tindakan yang membuat malu keluarga,s maka ia akan diusir atau dibunuh. Namun, adat ini sudah luntur di zaman sekarang ini. Tidak ada lagi keluarga yang tega membunuh anggota keluarganya hanya karena tidak ingin menanggung malu dan tentunya melanggar hukum. Meskipun demikian Adat malu (Siri') masih dijunjung oleh masyarakat Bugis kebanyakan walau tidak seketat dulu. Inilah salah satu nilai masyarakat Bugis, dan masih banyak yang lain.

Salah satu sumber penggambaran watak orang bugis dan sifat kebudayaannya ialah pangngajak tomatoa atau wasiat orang-orang dahulu. Pada dasarnya masyarakat bugis itu dibentuk mentalnya melalui pappaseng (istilah lain pangngajak). Wasiat itu awalnya hanya berupa lisan yang disampaikan atau dituturkan. Akan tetapi setelah masyarakah Bugis mengenal tulisan, wasiat-wasit itu pun ditulis dalam di atas daun lontar. Lontar adalah tanaman yang banyak Tumbuh di Sulawesi Selatan. Kumpulankumpulan tulisan itulah kemudian dikumpul sehingga terciptalah "Lontarak".

Dalam kedudukannya sebagai salah satu bentuk karya sastra Bugis, panggajak berfungsi sebagai sumber nilai. Artinya, di dalamnya kita dapat menemukan berbagai macam nilai yang harus dihormati terutama orang yang berlatar belakang budaya bugis. Nilai-nilai itu sekaligus merupakan dasar penilaian, apakah seseorang masih wajar disebut tau (manusia yang sebenarnya) atau hanya sekedar rupa tau (hanya berbentuk manusia).

Tau dalam hal konsep masyarakat bugis inilah yang disebut manusia yang ideal. Dikaitkan dengan konsep pendidikan karakter, nilai-nilai yang terkandung dalam Pappaseng orang bugis ini sangat bermanfaat untuk diterapkan kedalam pengajaran dan bimbingan tentang nilai-nilai budaya kepada siswa atau kepada masyarakat. Sehubungan dengan kasus demi kasus yang silih berganti mengganggu keutuhan dan 


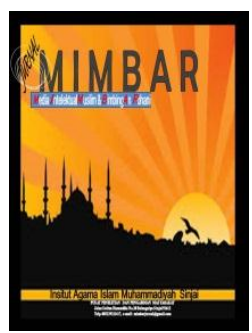

\section{MIMBAR}

Jurnal Media Intelektual Muslim dan Bimbingan Rohani

Volume 7, No. 1, 2021

ISSN (print) : 2442-3217

ISSN (online) : 2716-3806

Homepage : http://journal.iaimsinjai.ac.id/indeks.php/mimbar

kedamaian bangsa Indonesia, penulis merasa ada sesuatu yang hilang dari diri masyarakat. Sesuatu hal yang hilang itu adalah budaya pappaseng yang merupakan budaya masyarakat Bugis khususnya dan Indonesia secara umum. Masyarakat tidak lagi menjadikannya sebagai pedoman hidup. Oleh karena itu, penulis merasa perlu mengungkap kembali nilai-nilai pappaseng sehingga dapat menjadi sarana pengendalian diri bagi masyarakat. Hal yang terpenting adalah bagaimana melestarikan dan memodifikasi konsep pappaseng itu dimaknai dalam konteks yang lebih mudah dicerna karena seringkali kalimat-kalimat yang tertera dalam pappaseng berbentuk seperti majas. Jadi memerlukan penafsiran kata yang sangat dalam sehingga siswa bisa jadi mengalami kesulitan dalam memaknai hal tersebut.

\section{Metode}

Metode penelitian ini menggunakan pendekatan kualitatif dilakukan melalui proses penafsiran data. Adapun jenis penelitian menggunakan hermeneutika Gadamerian. Sebuah pendekatan yang bertujuan untuk menafsirkan atau menginterpretasikan buku-buku teks dengan tujuan mencari makna atau pemahaman baru dari buku teks yang telah ditafsirkan, Menurut Mappiare (2013) sifat umum riset hermeneutika berupaya untuk memahami, mendeskripsikan dan menginterpretasikan dunia realitas yang sesungguhnya yang tersembunyi didalam suatu teks.

Hermeneutika gadamerian adalah sebuah pendekatan yang menekankan pada dialogisasi didalam memahami sebuah teks. Kajian heremeneutika (Musbikin, 2016:43) berkembang sebagai sebuah usaha untuk menggambarakan teks, lebih khusus terkait mengenai pehaman historis dan humanistika. Sehingga dapat dikatakan heremenutika memiliki beberapa aspek. Pertama, pemahaman teks. Kedua, persoalan yang mengarah mengenai apa pemahaman interpretasi itu.

Analisis data yang digunakan menggunakan pola lingkaran atau pola Parts and Whole, yaitu pola penafsiran dengan menggunakan Parts yaitu bagian dan Whole yaitu keseluruhan dari teks yang digunakan. Artinya penafsiran dilakukan terhadap teks secara utuh tanpa melupakan bagian-bagian (Parts) penting di dalam teks itu 


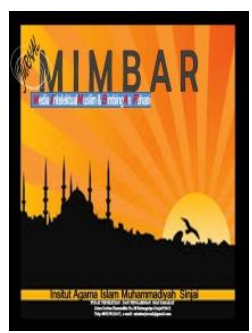

\section{MIMBAR}

Jurmal Media Intelektual Muslim dan Bimbingan Rohani

Volume 7, No. 1, 2021

ISSN (print) : 2442-3217

ISSN (online) : 2716-3806

Homepage : http://journal.iaimsinjai.ac.id/indeks.php/mimbar

sendiri. Menurut Alvesson dan Skoldberg (2000:53) Whole (keseluruhan) terdiri atas parts (bagian-bagian), hal ini hanya dapat dipahami atas dasar tersebut. Oleh karena itu, kita dihadapkan dengan sebuah lingkaran yang disebut hermeneutika circle (lingkaran), yaitu part (bagian) hanya dapat dipahami dari whole (keseluruhan) dan whole (keseluruhan) hanya didapat dari part (bagian). Sehingga disimpulkan bahwa part dan whole itu berhubungan satu sama lain.

\section{Hasil}

\section{"Nilai-Nilai Yang Terdapat Dalam Pappaseng Adat Bugis"}

Pappaseng sarat dengan makna dan pesan-pesan moral, karena di dalamnya terkandung nilai-nilai luhur yang dapat dijadikan pedoman hidup, sebagai pengatur tingkah laku pergaulan dalam masyarakat. Karena itu, perlu adanya upaya pengkajian secara serius guna mengungkap kembali nilai-nilai luhur yang terkandung di dalamnya terutama nilai edukatif yang sangat diperlukan untuk pembinaan karakter generasi sekarang dan generasi yang akan datang. Namun, pertanyaannya adalah bagaimanakah pappaseng itu bisa dijadikan sebagai media penididikan nilai dan karakter baik melalui jalur formal maupun melalui jalur informal. Ada beberapa nilai yang terdapat dalam pappaseng adat orang Bugis yang harus dimiliki oleh seseorang sehingga ia bisa di katakan tau (manusia yang ideal). Nilai-nilai tersebut adalah sebagai berikut (dalam Sikki, Rijal, Nasruddin, Syamsul Alam: 1998) :

\section{a. Siri'dan Pesse ( Harga Diri dan Empaty)}

Menurut pelras ( 2006: 251)dalam kehidupan manusia bugis_makassar, siri' merupakan unsur prinsipil dalam diri mereka. Tidak ada satu nilai pun yang paling berharga untuk dibela dan dipertahankan di muka bumi selai dari pada Siri'. Bagi manusia Bugis_Makassar, siri'adalah jiwa mereka, harga diri mereka dan martabat mereka. Sebab itu, untuk menegakkan dan membela Siri' yang dianggap tercemar atau di cemarkan oleh orang lain, maka manusia Bugis- Makassar akan bersedia 


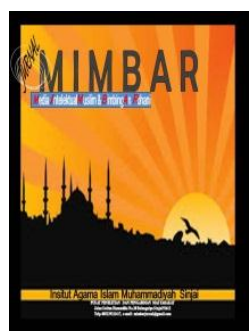

\section{MIMBAR}

Jurmall Media Intelektual Muslim dan Bimbingan Rohani

Volume 7, No. 1, 2021

ISSN (print) : 2442-3217

ISSN (online) : 2716-3806

Homepage : http://journal.iaimsinjai.ac.id/indeks.php/mimbar

mengorbankan apa saja, termasuk jiwanya yang paling berharga demi tegaknya Siri' dalam kehidupan mereka.

Akan tetapi dalam kehidupan sehari-hari, efek siri' bisa juga memberi dampak negatif jika masyarakat terlalu menjadikannya sebagai pedoman dengan penilaian yang sangat kaku. Oleh karena itu istilah pesse kemudian muncul sebagai nilai dalam menyeimbangkan kekakuan akan nilai siri. Pesse adalah pesse bua( rasa kasihan) dalam artian bagaimana kita bisa merasakan penderitaan orang lain, rasa kasihan, dan keinginan untuk tidak melukai. Inilah kemudian yang bisa dikaitakan dengan konsep empaty dalam psikologi. Mengapa siri' na pecce merupakan dua hal yang tidak boleh dipisahkan? Karena ketika siri sedang dipertaruhkan yang menyebabkan munculnya keinginan untuk membalas orang yang menginjak martabat dan harga diri, pesse kemudian muncul sebagai penyeimbang, penetral, dan sebagai malaikat yang bisa mengontrol emosi tersebut. Adanya nilai pesse menjadikan masyarakat tenteram dan tidak terjadi pertikaian. Nilai pesse masih memandang bahwa manusia tidak pantas untuk dilukai bagaimana pun bentuk kesalahan yang mereka perbuat.

\section{b. Awaraningeng (Keberaniaan)}

Seorang pemberani dapat dikenali dengan memperhatikan tindakan dan perilaku dalam menyikapi masalah yang dihadapinya. Sikap yang dimaksud antara lain adalah tidak gentar melakukan pekerjaan, baik yang sulit maupun yang mudah yang mudah menurut patutnya. Ia berani mengucapkan perkataan yang keras maupun yang lemah lembut menurut wajarnya. Demikian pula, ia tidak ragu-ragu memutuskan perkara yang sulit maupun yang mudah sesuai dengan kebenaran. Selanjutnya, ia tidak segan mengingatnya serta menasehati para pembesar maupun orang awam berdasarkan kebenaran yang diyakini.

Bebeberapa orang arif bijaksana tentang keberanian yang terkandung dalam pappaseng (1998:29) adalah:

akgurui gaukna tau waranie enrenge ampena, apak iya gaukna towaranie seppuloi uwangenna naseuwamua jakna, jajini asera decenna, nasabak iyanaro nariaseng jakna seddie malamoi naola 
Volume 7, No. 1, 2021

ISSN (print) : 2442-3217

ISSN (online) : 2716-3806

Homepage : http://journal.iaimsinjai.ac.id/indeks.php/mimbar

amatengenge. Naekiya mau tau pelloreng matemuto, apak dessa, temmatena sininna makkenyawae. Naiya decenna aserae:

a. Tettakinik napolei karena majak kareba madeceng

b. Dekna jampangiwi karena naengkalingae, naekiya napaesilaongngi sennang ati pikkirik madeceng

c. Temmemtauni ripariolo

d. Temmatauni ripamunri

e. Tetteyai mita bali

f. Rialai passappo riwanuae

g. Matinuluk i pajajai passirong

h. Riallai paddebang tomawatang

i. Masriktoi, riyaksiritoi, ripaddana tau

Terjemahan:

Pelajari tingkah laku pemberi. Ada sepuluh macam tingkah laku pemberani. Hanya satu keburukannya, tetapi sembilan kebaikannya. Ia dikatakan buruk karena mudah terancam kematian. Namun, orang penakut pun takkan luput dari maut karena setiap nyawa mengalami kematian. Perilaku seorang pemberni ada sembilan macam:I

a. Tidak terkejut mendengar kabar buruk atau baik

b. Tidak panik menerima kabar yang didengar tetapi diterimanya denga tenang dan pikiran sehat.

c. Tidak takut tampil kedepan

d. Tidak takur ditampilkan dibelakang

e. Tidak gentar melihat musuh

f. Menjadi perisai bagi negara

g. Menjadi perisai bagi negara

h. Tekun melaksanakan kewajiban

i. Menjadi benteng penangkal kesewenang-wenangan

j. Segan menyegani sesama manusia

\section{c. Reso (Etos kerja)}

Untuk memenuhi kebutuhan hidup, manusia harus bekerja. Keberhasilan seseorang dalam melaksanakan pekerjaan atau menjalankan usahanya itu berbedabeda. Kesuksean dan kegalagn dalam meraih kehidupan yang layak dan bercukupan pada hakekatnya tergantung pada rejeki dan nasib seseorang. Manusia diwajibkan berusaha dan bekerja keras, rahmat tuhan diharapkan dapat tercurahkan. Hal itu sesuai dengan pappaseng yang berbunyi "resopa temmangngingngi naletei pammse 


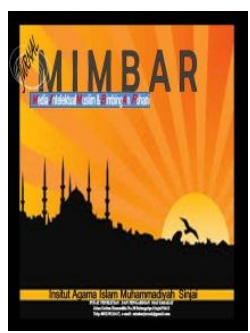

\section{MIMBAR}

Jurmal Media Intelektual Muslim dan Bimbingan Rohani

Volume 7, No. 1, 2021

ISSN (print) : 2442-3217

ISSN (online) : 2716-3806

Homepage : http://journal.iaimsinjai.ac.id/indeks.php/mimbar

Dewata artiya "hanya dengan ketekunan kerja, rahmat Tuhan diperoleh. Jadi salah satu syarat untuk meraih kesuksesan dala kehidupan adalah kerja keras. Banyak fakta yang membuktikan bahwa orang-orang yang berhasil meraih kesuksesan dalam hidup mereka yang memeiliki etos kerja yang tinggi. Seperti yang diungkapakan dalam pappaseng orang bugis adalah sebagai berikut:
iae wettue
sitinajai ripakkeguna wettu
ia naritu tau kuttu
kuttue teppauno
poleanna kuttue temmapakbinasa
ia kia pasussai napasessa
kuae topa mappanrasa-rasa
Terjemahan:
Pada saat sekarang ini
Sepatutnya waktu itu dimanfaatkan
Orang yang tak menggunakan waktu
Orang itu seperti pemalas
Kemalasan memang tak membunuh
Hasil kemalasan tak membinasakan
Tetapi menyulitkan dan menyiksa
Serta membuat sengsara
Pappaseng lain:
Matukpae, bajapae, temmappapura jama-jamang
Terjemahan:
Sebentar, besok, nanti tidak akan akan menyelesaikan pekerjaan.

Hal ini bermakna suatu perkerjaan tidak baik ditunda, karena dapat menimbulkan kerugian. Orang yang selalu menunda waktu berarti tidak pernah memulai dan barang siapa yang tidak pernah memulai berarti tidak pernah pula mengakhiri.

\section{d. Alempureng (Kejujuran)}

Kejujuran merupakan landasan pokok dalam menjalin hubungan dengan sesama manusia. Kejujuran merupakan landasan pokok utama dalam menjalin hubungan dengan sesama manusia. Terjadinya ketidakjujuran dalam masyarakat akan menimbulkan bencana berupa ketidakberhasilan. Kejujuran merupakan syarat mutlak 


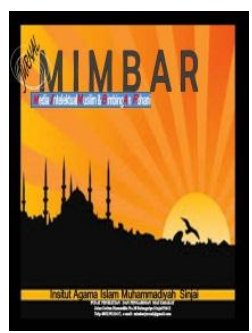

\section{MIMBAR}

Jurmal Media Intelektual Muslim dan Bimbingan Rohani

Volume 7, No. 1, 2021

ISSN (print) : 2442-3217

ISSN (online) : 2716-3806

Homepage : http://journal.iaimsinjai.ac.id/indeks.php/mimbar

untuk dimiliki oleh seseorang yang akan diangkat menjadi raja-raja dan pejabat kerajaan.

Terjadinya ketidak jujuran dalam masyarakat akan menimbulkan bencana berupa tidak berhasilnya segala tanaman, serta tumbuhnya segala penyakit. Disamping itu, kejujuran merupakan syarat yang mutlak untuk dimiliki oleh seseorang yang akan diangkat menjadi raja dan pejabat-pejabat kerajaan. Hal ini dapat dapat kita lihat dari berbagai naskah orang lama orang bugis yang berupah pappaseng adalah sebagai berikut:

“ duami kuala sappo unganna panasae nabelo kunukue" artinya ada dua yang kujadikan sebagai pagar, bunga nangka dan penghias kuku. Dalam bahasa bugis bunga nangka dinamakan lempu yang artinya Jujur, penghias kuku dalam bahasa bugis dinamakan paccing artinya bersih. Jadi dapat disimpulkan dari ungkapan tadi bahwa ada dua hal yang menjadi dasar terciptanya hubungan sesama manusia yang menyebabkan kemakmuran bersama, yaitu jujur dan bersih.

Sejarahnya bahwa ada seorang nenek Moyang yang bernama Nenek Mallomo. Beliau adalah seorang yang setia membela dan menegakkan kejujuran dan telah berhasil menciptakan kesejahteraan rakyat Sidenreng di bawah naungan lembaga peradilan yang beribawa.

“ eppak i gaukna lempuk E

Risalaie naddampeng

Riparennnungie temmaceko bettuanna risanresie

Teppabelleang"temmangoangengi tania olona"

Tennaseng deceng rekko nassamarini pudeceng

Maksudnya

Ada empat perbuatan juju itu:

Memaafkan orang yang bersalah kepadanya:

Dipercaya lalu tidak curang, artinya disandari

Lalu tidak mengecewakan, tidak serakah terhadap

Yang bukan haknya:dan tidak memandang kebaikan

Kalau hanya dirinya, baginya baru dinamakan

Kebaikan jika dinikmati bersama.

\section{e. Getteng (Keteguhan)}




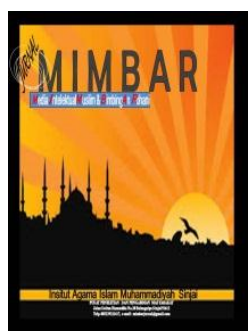

\section{MIMBAR}

Jurmal Media Intelektual Muslim dan Bimbingan Rohani

Volume 7, No. 1, 2021

ISSN (print) : 2442-3217

ISSN (online) : 2716-3806

Homepage : http://journal.iaimsinjai.ac.id/indeks.php/mimbar

Keteguhan pendirian dalam bahasa bugis disebut getteng. Kata getteng meliputi banyak pengertian seperti tegas, tangguh, teguh pada keyakinan, dan taat asa. Dilihat dari dampak yang ditimbulkan, keteguhan itu dapat bernilai positif dapat pula bernilai negatif.

Keteguhan itu dilukiskan dalam papaseng yang antara lain seperti berikut:

Magetteppi'. Bettuanna tessalai janci, magetteng toi ala nasorosie ulu ada, enrenge telluka bicara pura. Nagettengi toi ala mesak'e beccik, namagettengto ala napalekbi'e pangkaukenna, enrengnge arega ala nakurangie pangkaukenna. Namagetteng tona la napalekbie ada-adanna, iarega ala nekurangie ada-adanna enrengnge napalekbie pakkitana ri pura nitae. Tennapalekbi toni pura naengkalingae, enrenge topa pakdessengna, tongeng-tongeng, megettengngie sininna pura rirampe.

Terjemahan:

Teguh pendiriannya. Artinya, ia tidak meninggalkan janji, ia juga teguh memegan ikrar dan tidak akan memantahkan keputusan hakim. Ia teguh pada batas-batas yang sudah ditentukan, tidak melebihlebihkan perbuatannya, dan tidaka juga menguranginya. Ia teguh juga untuk tidak melebih-lebihkan penglihatannya dari apa yang sudah dilihatnya. Demikian juga pendengarannya serta pengetahuannya dari apa saja yagn telah diketahuinya. Orang yang teguh memegang apa yang sudah disebutkan tadi, itulah orang yang sungguh-sungguh teguh pendiriannya.

\section{f. Solidaritas}

Nilai solidaritas ialah nilai-nilai yang mengatur dan mempengaruhi cara membina hubungan antara sesama manusia, baik hubungan antara sesama manusia, baik hubungan antarindividu maupun kelompok masyarakat sehingga terjadi hubungan yang baik dan harmonis. Hal itu dapat disimak melalui pappaseng seperti yang diutarakan di bawah ini.

Iya peddecengi asseajingeng

a) Sianrasa-rasangnge nasiamese-masei

b) Sipakario-rio

c) Tessicirinnaiengnge risitinajae 
d) Sipaingek rigauk patujue

e) Siaddampengeng pulanae Artinya:

Yang memperbaiki hubungan kekeluargaan:

a) Sependeritaan dan saling kasih-mengasih

b) Saling menggembirakan

c) Saling merelakan harta benda dalam batas-batas yang pantas

d) Saling mengingatkan dalam hal-hal yang benar

e) Selalu saling memaafkan.

Pada dasarnya, pappaseng di atas memberikan hal-hal yang dapat memperbaiki hubungan kekeluargaan. Namun, jangkauan pemikiran yang terkadung didalamnya dapat pula diaplikasikan pada hubungan yang sosial kemasyarakatan. Setiap pappaseng di atas masing-masing mempunyai nuansa makna tersendiri tetapi antara satu dengan lainnya saling menguatkan.

Kasih-mengasihi dalam penderitaan merupakan simpul ikatan batin yang mempertautkan hati denga hatim pikiran dengan pikiran. Rasa persamaan seperti itu merupakan modal yang sangat berharga yang selalu optimis memandang hari esok yang lebih cerah sehingga suasana gembira senantiasa mewarnai kehidupan. Untuk memperat rasa kebersamaan itu, semangat tolong-menolong perlu dipupuk dan dipelihara dengan berbagai cara, misalnya, saling merelakan benda batas-batas yang pantas. Selanjutnya, apabila terjadi penyimpangan atau kekeliruan yang dapat meretakkan hubungan hendaknya cepat di atasi dan diselesaikan dengan seling memperingati dan saling memaafkan.

\section{g. Teppe' ri Dewatae (Kepercayaan terhadap Tuhan)}

Dalam pappaseng, ditemukan banyak nilai keagamaan. Hal itu dapat dimengerti karena orang Bugis sejak dahulu sudah mempercayai adanya Tuhan sebagai pencipta alam semesta yang mereka sebut Dewatae. Nilai keagamaan dalam pappaseng pada umumnya membahas pengertian dan keyakinan yang sebenarnya tentang hakikat dan sifat Tuhan, pengabdian dan kewajiban manusia terhadap Tuhan, 


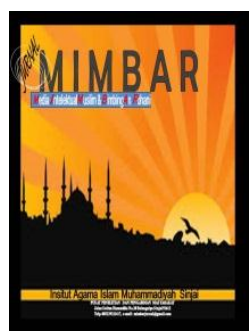

\section{MIMBAR}

Jurmal Media Intelektual Muslim dan Bimbingan Rohani

Volume 7, No. 1, 2021

ISSN (print) : 2442-3217

ISSN (online) : 2716-3806

Homepage : http://journal.iaimsinjai.ac.id/indeks.php/mimbar

tata hubungan antara manusia dan manusia sertaakhlak yang mulia. Keyakinan terhadap Tuhan terkandung dalam pappaseng berikut ini

\section{h. Abbulo sibatang (Persatuan)}

Nilai persatuan itu tumbuh dalam ikatan keluarga dan organisasi kemasyarakatan. Dengan persatuan berbagai persoalan dapat di atasi, yang berat menjadi ringan, yang sulit menjadi mudah. Nilai persatuan itu kadang-kadang menghadapi ujian berat terutama pada saat yang kritis atau dalam menghadapi penderitaan. Dalam hubungan itu pappaseng menghimbau agar persatuan itu senantiasa dipertahankan dalam menghadapi berbagai situasi. Nilai persatuan dalam masyarakat Bugis dapat ditelusuri leat pappaseng seperti terungkap di bawah ini:

Naia masseuana taue, aruai uwangenna. Riaseng mattau seua. Seuani massiruntui ri lalepanua. Madduanna, siallempurengngi. Mettelluna, siakkeda tongengi. Maeppana, siasirri. Malimanna, ja nauru, deceng nauru. Maennenna, sitereng ri bulue, tessinoreng ro lompok-e. Mappitunna, tessicirinnaiangngi ri silasanae. Maruana, sipattongngngi ri akkuanae. Nariasenna makbulo silampa, malibu ri saliweng. Naia ittello, mapute na malibu tampu ulau. Ulauwe mancaji manuk. Manuk-e si makkitelloreng itello. Aga naian riasengnge malibu ettello, de makdioloiwi, deto makdimunringiwi.

Terjemahan : ada delapan unsur yang menjadi kriteria persatuan rakyat. Pertama, mereka yang seia sekata dalam negeri. Kedua, mereka jujur sesamanya. Ketiga, mereka saling tenggang rasa. Kelima, dalam suka dan duka mereka bersatu. Keenam, ke gunung sama mendaki, ke luarah sama menurun. Ketujuh, tak enggan saling membenarkan menurut apa adanya. Maka yang demikian itu diibaratkan bagai buluh sebatang, bulat bagaikan telur. Buluh itu bundar didalam, bundar juga di luar. Adapun telur itu, putih lagi bulat, intinya itulah menjadi ayam. Ayam itu lagi yang menghasilkan telur. Maka yang dinamakan bulat bagaikan telur, tidak ada yang mendahuluinya, tidak ada pula di belakangnya.

\section{i. Appasitinajang (Keselarasan)}

Keselarasan merupakan neraca yang mengatur keseimbangan dalam hidup dan kehidupan manusia. Kehidupan yang tidak bertumpu pada keselarasan tidak akan pernah mengalami ketentraman dan kebahagian. Hakikat kebahagian hidup yang 


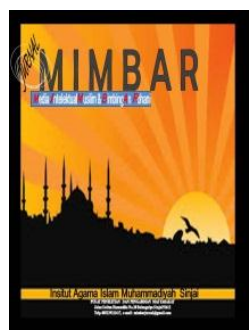

\section{MIMBAR}

Jurmal Media Intelektual Muslim dan Bimbingan Rohani

Volume 7, No. 1, 2021

ISSN (print) : 2442-3217

ISSN (online) : 2716-3806

Homepage : http://journal.iaimsinjai.ac.id/indeks.php/mimbar

sejati tidak lain adalah keselarasan kehidupan jasmani dan rohani serta keselarasan duniawi dan ukhrawi. Dalam praktik, keselarasan itu dapat dijabarkan dalam berbagai aspek kehidupan, seperti keselarasan dalam mengatur urusan rumah tangga, keselarasan dalam membina hubungan pergaulan bahkan keselarasan dalam mengendalikan kehidupan pribadi atau diri sendiri. Salah satu perwujudan keselarasan dalam mengendalikan kehidupan pribadi ialah keselarasan antara ucapan dan perbuatan. Berikut ini pappaseng yang mengandung nilai keselarasan dapat dilihat seperti berikut ini:

\section{Pasiceppek-i lilamu nabatelamu}

Terjemahan: selaraskan lidahmu dengan jejakmu.

Hal ini berhubungan dengan public trust. Banyak sekali orang yang tidak bisa menyelaraskan antara ucapan dan tindakannya. Perilaku seperti itu tentunya mempunyai citra yang buruk dimata masyrakat karena nilai seseorang ditentukan pula oleh kemampuannya menyelaraskan ucapan dan perbuatannya. Kemampuan seseorang untuk membuktikan perkataan dan perbuatannya akan menimbulkan rasa simpati dan penghormatan masyarakat kepadanya. Demikian pula sebaliknya, orang yang sering berbuat sesuatu yang bertentangan denganyang diucapkan, akan kehilangan kepercayaan masyarakat kepadanya.

\section{Pembahasan}

Lickona menjelaskan bahwa (2012:7) pendidikan karakter dan moral pada dasarnya bukanlah topik baru dalam pendidikan. Pada dasarnya pendidikan memiliki dua tujuan, yaitu membimbing para genarasi muda untuk menjadi cerdas dan memiliki perilaku berbudi. Seiring dengan berjalannya waktu, berbagai pandangan yang mendukung pendidikan karakter yang bersifat klasikpun hilang.

Di Negara Korea ( Leang-lee, 2013) pendidikan karakter tradisional menjadi sebuah aspek penting dari sistem pendidikan yang melibatkan orang tua untuk menanamkan dalam diri nilai-nilai dalam diri anak mereka. Dalam hal ini dikaitkan dengan adanya nilai-nilai pappaseng, orang tua bisa melibatkan diri ataupun guru 


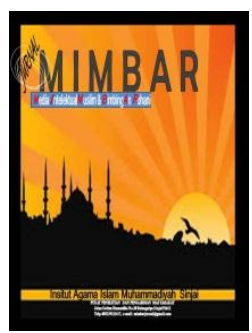

\section{MIMBAR}

Jurmal Media Intelektual Muslim dan Bimbingan Rohani

Volume 7, No. 1, 2021

ISSN (print) : 2442-3217

ISSN (online) : 2716-3806

Homepage : http://journal.iaimsinjai.ac.id/indeks.php/mimbar

untuk menanamkan nilai tersebut mulai anak kecil sampai pada akhirnya mereka bisa menjadi pribadi yang mandiri. Sehingga nilai-nilai yang telah ditanmakan mampu diaplikasikan kedalam kehidupannya sehari, misalnya ketika ia mampu bersosialisi dalah dunia kerja mereka kelak atau di dunia sosial lain.

\section{a. Siri dan Pesse ( Harga Diri dan Empaty)}

Apabila harga diri terlalu dipertaruhkan dalam kehidupan sehari-hari akan memberi dampak negatif. Oleh karena itu sangat di perlukan empaty untuk menetralkan perasaan, sehingga ada keinginan untuk lebih mengerti orang lain. Tanpa melihat sebelah mata. Salah satu hal yang penting digarisbawahi adalah keterangan Pelras bahwa konsep siri' dalam filsafat hidup orang Bugis, sesungguhnya tidak berdiri sendiri, melainkan ada'pasangannya', yakni pesse', atau lengkapnya, pesse'babua, yang berarti “ikut merasakan penderitaan orang lain dalam perut sendiri”. Jadi di samping harga diri orang Bugis yangbegitu tinggi, mereka juga memiliki empati terhadap penderitaan tetangga, kerabat, atausesama anggota kelompok sosial. Alangkah indahnya bunyi pepatah (dalam Aditjonro: 2006), pauno siri', ma 'paletepesse' ri pa'masareng esse'. Atau, "kehormatan bisa menyebabkan kematianmu, dan rasa iba bisa membawamu ke alam baka”. Maksudnya, antara siri' dan pesse' harus tetap ada keseimbangan agar bisa saling menetralisir titik ekstrim masing-masing.

Karakter seperti inilah kemudian yang sangat penting untuk diturunkan kepada peserta didik, dan masyarakat pada umumnya. Sesuai dengan pemaparan dettinger \& hart (dalam Yang, Dongsu: 2007) menyatakan bahwa sifat agresi seseorang di akibatkan oleh harga diri yang rendah. Hal ini membuktikan bahwa ada pengaruh yang sangat besar antara harga diri yang sifat agresi. Inilah kemudian pentingnya empaty di ajarkan kepada peserta didik untuk memahami orang lain lebih dalam.

Karakter ideal yang berhubungan dengan temuan ini juga ditunjukkan dalam hasil penelitian Muslifar (2020) mengenai karakter ideal konseli dalma masyarakat 


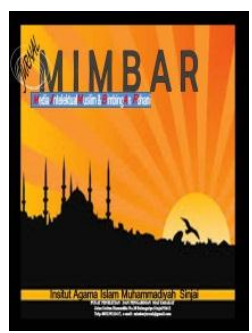

\section{MIMBAR}

Jurmal Media Intelektual Muslim dan Bimbingan Rohani

Volume 7, No. 1, 2021

ISSN (print) : 2442-3217

ISSN (online) : 2716-3806

Homepage : http://journal.iaimsinjai.ac.id/indeks.php/mimbar

desa yang menunjukkan bahwa (1) pribadi yang setiakawan, (2) memiliki keyakinan pada tuhan, ruh, manusia dan alam, dan (3) kebiasaan hidup sederhana.

\section{b. Awaraningeng (Keberaniaan)}

Keberanian adalah salah satu karakter nilai yang dimiliki oleh masyarakat bugis. Ini adalah turunan nilai yang menurut kajian karakter, keberanian itu timbul dari siri (harga diri). Untuk menjaga harga diri, maka keberanian adalah salah satu aspek yang mendukung untuk mempertahankan nilai tersebut. Akan tetapi, kadang kala ada orang Bugis terlalu berlebihan dalam memandang ini. Sehingga muncul takabboro (takabur), maborro (sombong). Sifat seperti inilah yang harus dihindari dalam kehidupan sosial dimana ada unsur percaya diri yang terlalu tinggi sehingga kadang merendahkan orang lain (Acciaioli : 2004).

Keberanian (Gouthro: 2013)adalah kualitas batin yang menjadijelas ketika Anda mengambil tindakan di mana masing-masing dari tiga kriteria berikut inidipenuhi: (i) ada pasti atau Hasil tak terduga, (ii) adaemosi atau perasaan sekarang yang berkisarsuatu tempat antara keprihatinan ringan danteror (berdasarkan dirasakankonsekuensi dari kegagalan), dan (iii) adanilai positif atau keyakinan yangsadar atau tidak sadar dari tindakan Anda.

Dalam pappaseng juga Hakim menuliskan ( 1992:33) ada empat macam kayu rapuh itu, pertama, yang mengandalkan turunan atau asal usul; kedua, yang mengandalkan kepintaran; ketiga, yang mengandalkan kekayaan, dan yang terakhir adalah mengandalkan keberanian. Mengapa hal tersebut dikatakan kayu rapuh? Karena ke empat unsur tadi tidak bisa dijadikan sebagai sandaran hidup. Akhirnya kita akan menjadi manusia yang rapuh.

\section{c. Reso (Etos kerja)}

Etos kerja sangat erat kaitannya dengan kepuasan atas hasil kerja yang diperoleh (Rohman, 2010).Etos kerja dalam hal ini diartikan sebagai kerja keras ketika mengerjakan sesuatu. Ada kesungguhan yang mendalam ketika sedang menekuni 


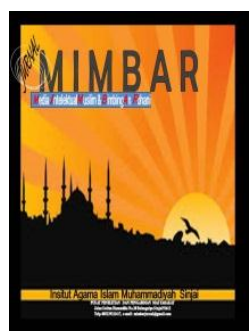

\section{MIMBAR}

Jurmal Media Intelektual Muslim dan Bimbingan Rohani

Volume 7, No. 1, 2021

ISSN (print) : 2442-3217

ISSN (online) : 2716-3806

Homepage : http://journal.iaimsinjai.ac.id/indeks.php/mimbar

sesuatu. Nilai ini yang harus dimiliki oleh masyarakat secara umum, dan kepada peserta didik secara khusus. Plagiasi dan menyontek adalah salah satu penyakit peserta didik ( siswa dan mahasiswa) yang membudaya.Banyak studi tambahan telah berusaha untuk menentukan faktor - spesifik mahasiswa dan kampus yang mempengaruhi mengapa siswa menyontek. Karakteristik individu siswa yang mempengaruhi ketidakjujuran akademik meliputi usia, jenis kelamin, nilai rata-rata, dan keanggotaan dalam persaudaraan atau perkumpulan (Baird, 1980; Burrus, McGoldrick, dan Schuhmann, 2007; Lambert, Ellen, dan Taylor, 2003; Leming, 1980; McCabe dan Trevino, 1997).

Berhubungan dengan etos kerja ada dua hal yang mempengaruhi kesuksesan kerja seseorang yaitu mengenai definisi diri dan definisi situasi. Menurut Fitriana (2019), kesuksesan seseorang dipengaruhi oleh Definisi diri Superior dan Enabling Factor dalam definisi situasi

\section{d. Alempureng (Kejujuran)}

Dalam pergaulan sosial masyarakat bugis nilai kejujuran dipandang tinggi dan ideal. Sebaliknya mereka mencela mereka akan mencela perbuatan dan perkataan dusta dan kemunafikan. Masyarakat bugis menempatkan kesehatan nilai kejujuran itu sama bobotnya dengan keutamaan menulis kitab, di samping keutamaan aspek kesehatan jasmani dan rohani (dalam Yunus, Hamis, Raja, Kartikasari: 1995).

\section{e. Getteng (Keteguhan)}

Keteguhan hati merupakan hal yang sangat penting dalam kehidupan manusia. Ketika kita tidak mempunyai nilai keteguhan dalam diri, maka kita tidak lagi dikatakan manusia, akan tetapi hanyalah sebatas tau-tau (menyerupai manusia). Keteguhan dalam hal bisa dikaitkan dengan ketabahan. Ketabahan didefinisikan (dalam Pretorius dan Heyns: 2005) sebagai kekuatan untukmengelola stres dan tetap baik dan kekuatan ini berasal dari suatu penilaian daridiri, keluarga dan dukungan dari orang lain. Ketabahan pada dasarnya, karena itu adalah kekuatan yang berasal 


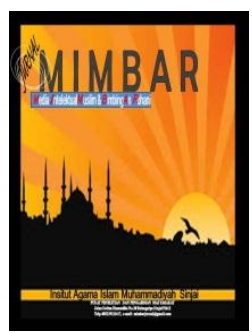

\section{MIMBAR}

Jurmal Media Intelektual Muslim dan Bimbingan Rohani

Volume 7, No. 1, 2021

ISSN (print) : 2442-3217

ISSN (online) : 2716-3806

Homepage : http://journal.iaimsinjai.ac.id/indeks.php/mimbar

dari diri kita sendiri dan menilaidunia kita positif, memungkinkan kita untuk mengatasi stres kehidupan.

Sifat tahan banting didefinisikan sebagai konstruksi kepribadian yang terdiri dari dimensi :(a) rasa kontrol atas peristiwa yang berpengalaman, (b) perasaankomitmen untuk berbagai bidang kehidupan, dan (c) pandangan perubahan hidup sebagai tantangan.

\section{f. Solidaritas}

Dalam sebuah artikel (Sustein, Margalit: 2001) mengungkapkan bahwa ketika sebuah kelompok yang berkualitas berpengaruh, maka banyak orang yang akan bergabung di dalam kelompok tersebut, karena hal itu akan menciptakan positive solidarity externalities ( eksternalisasi solidaritas positif). Akan tetapi solidaritas merupakan ialah yang memiliki dampak negatif juga. Seperti yang terlihat dalam tatangan televisi bahwa kebanyakan tawuranyang terjadi pada kelompok pelajar disebabkan karena alasan solidaritas.

\section{g. Teppe' ri Dewataeatausara' (Kepercayaan terhadap Tuhan)}

Tipologi Sara' sebagai control spiritual dalam (kahar, Triyuwono, Irianto, Ludigdo: 2013) kegunaan nilai, norma dan konsep berasal dari kitab agama atau ritual budaya dalam praktek mereka untuk berserah diri kepada Tuhan sebagai kontrol mental mereka. Tipologi kontrol spiritual dapat dilakukan dengan memperkuat berikut nilai-nilai spiritual : (1) Tauhid (keesaan) nilai akan membuat karyawan agama, manajemen dan pemilik, pribadi yang percaya bahwa Tuhan hadir dalam setiap kegiatan dan usaha, (2) Ikhlas (bersedia), nilai ketulusan yang muncul ketika niat untuk melakukan praktek hanya untuk Allah, bukan karena riya ( ingin dilihat oleh manusia ) atau sum'ah (ingin didengar oleh manusia ), tidak karena Anda ingin mendapatkan pujian dan posisi yang tinggi antara orang-orang, (3) Integritas dan nilai-nilai kepercayaan, dalam bentuk tanggung jawab yang lebih tinggi pada tugas sesuai dengan tugas dan fungsinya, (4) Nilai-nilai keadilan, ini berarti bahwa manusia 


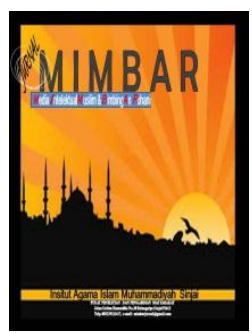

\section{MIMBAR}

Jurmal Media Intelektual Muslim dan Bimbingan Rohani

Volume 7, No. 1, 2021

ISSN (print) : 2442-3217

ISSN (online) : 2716-3806

Homepage : http://journal.iaimsinjai.ac.id/indeks.php/mimbar

pada dasarnya memiliki kapasitas dan energi untuk melakukan keadilan dalam setiap aspek kehidupan, (5) Istiqomah dalam bertindak untuk memfasilitasi semua pihak untuk bekerja sama dengan mudah. Istiqomah berarti tegak dan lurus dan tidak condong ke jalan-jalan lain yang terjun ke jurang kebinasaan. Tipologi Ade ' (kontrol diri) adalah proses mengendalikan perilaku oleh satu orang yang menggunakan energi atau kemampuan yang berasal dari dirinya sendiri. Merujuk sebagai kontrol pribadi yang menekankan pada karyawan (manusia).

\section{h. Abulo Sibatang (Persatuan)}

Ada delapan unsur yang menjadi kriteria persatuan rakyat dalam Hakim (1992: 78) Pertama, mereka yang seia sekata dalam negeri. Kedua, mereka jujur sesamanya. Ketiga, mereka saling tenggang rasa. Kelima, dalam suka dan duka mereka bersatu. Keenam, ke gunung sama mendaki, ke luarah sama menurun. Ketujuh, tak enggan saling membenarkan menurut apa adanya. Maka yang demikian itu diibaratkan bagai buluh sebatang, bulat bagaikan telur. Buluh itu bundar didalam, bundar juga di luar. Adapun telur itu, putih lagi bulat, intinya itulah menjadi ayam. Ayam itu lagi yang menghasilkan telur. Maka yang dinamakan bulat bagaikan telur, tidak ada yang mendahuluinya, tidak ada pula di belakangnya.

Ting - Toomey dalam (Bond dan Smith : 1996) mengemukakan bahwa dalam semua anggota budaya berusaha untuk menyelamatkan muka ketika menghadapi potensi malu, tetapi dalam budaya individualis fokusnya adalah paling kuat pada"Aku" aktor, sedangkan dalam budaya kolektivis fokusnya adalah pada "Kami". Kolektivitas Orang saling bergantung yang bersangkutan bahwa perilaku tidak benar mempermalukan orang lain serta menyebabkan kehilangan muka pribadi dan bahwa mereka dan anggota kelompok lainnya berusaha untuk mengantisipasi dan mendahului terjadinya peristiwa yang memalukan.

Pemaparan diatas menekankan bahwa ada unsur persatuan dalam konteks "kami" ketika ada sesuatu yang terjadi di antara mereka, maka massa yang terdapat 


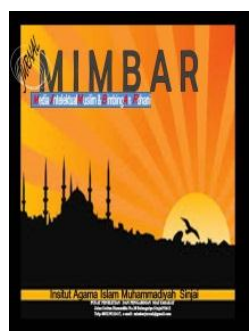

\section{MIMBAR}

Jurmal Media Intelektual Muslim dan Bimbingan Rohani

Volume 7, No. 1, 2021

ISSN (print) : 2442-3217

ISSN (online) : 2716-3806

Homepage : http://journal.iaimsinjai.ac.id/indeks.php/mimbar

didalam kelompok tersebut merasakan hal yang sama. Yaitu merasa malu. Itulah kemudian wujud satu yang berada salam satu kelompok.

\section{i. Appasitinajang (Keselarasan)}

Hal ini berhubungan dengan kehidupan Agama dan spiritual. Hal ini berhubungan aspek transedental. Bahwa sebagai manusia, kita harus percaya bahwa ada sesuatu yang berdaa di luar jangkauan kita sebagai mahluk Tuhan. Ada kekuatan besar yang merupakan kekuatan paling besar di alam semesta ini. Kesadaran akan hal itu sangatlah penting untuk mendidik peserta didik menjadi manusia yang selalu bersyukur, berdoa dengan usaha. Sehingga tidak menjadikan mereka sebagai mahluk yang terlalu takabbur dan tidak percaya akan kekuasaan Tuhan.Kita harus menyelaraskan antara kehidupan duniawi dan ukhrawi

\section{Simpulan}

Pappaseng Bugis memiliki nilai-nilai yang arif dan bijaksana. Nilai tersebut lahir dari praktek lokal, hasil dari pembacaan terhadap alam dan manusia. Nilai-nilai yang lahir dari masyarakat tersebut, sudah semestinya dipertahankan, sebagai suatu identitas etnik. Nilai-nilai dalam pappaseng Bugis menunjukkan bahwa individu yang ideal adalah Siri dan Pesse ( Harga Diri dan Empaty), Awaraningeng (Keberaniaan), Reso (Etos kerja), Alempureng (Kejujuran), Getteng (Keteguhan), Solidaritas, Teppe’ ri Dewataeatausara' (Kepercayaan terhadap Tuhan), Abulo Sibatang (Persatuan), dan Appasitinajang (Keselarasan). Karakter ideal tersebut berimplikasi terhadap karakter ideal konseli dalam layanan bimbingan konseling, sebagaimana pandangan bahwa konseli juga adalah manusia.

Ada banyak nilai yang bisa diserap dari nilai pappaseng masyarakat Bugis. Hal ini bisa dijadikan sebagai rekomendasi dalam pelaksanaan konseling lintas budaya. Hal penting yang bisa dipetik bahwa setiap budaya memiliki ciri khas 


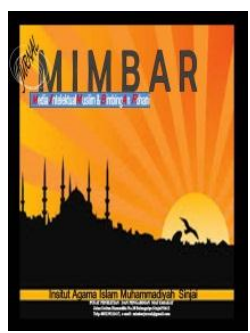

\section{MIMBAR}

Jurmal Media Intelektual Muslim dan Bimbingan Rohani

Volume 7, No. 1, 2021

ISSN (print) : 2442-3217

ISSN (online) : 2716-3806

Homepage : http://journal.iaimsinjai.ac.id/indeks.php/mimbar

tertentu yang tentunya merupakan bentuk pola pikir yang pasti baik untuk masyarakat pengikutnya. Pencapaian tentang sosok tau (manusia ideal) dalam konsep bugis bisa dijadikan referensi untuk mencapai tujuan konseling yaitu mencapai konseli yang ideal yang mampu menavigasi hidupnya sendiri dalam pengambilan keputusan hidup.

\section{Daftar Pustaka}

Acciaioli, Greg. 2004. From Economic Actor ToMoral Agent: Knowledge, FateAnd Hierarchy Among TheBugis Of Sulawesi. (online) http://varanidae.org/1_2-Koch_and_Acciaioli.pdf

Aditjondro, George Junus. 2006. Terlalu Bugis-Sentris, Kurang 'Perancis. (online). https://www.google.com/url?sa=t\&rct=j\&q=\&esrc=s\&source=web\&cd=2\&ca $\mathrm{d}=$ rja\&ved=0CDMQFjAB\&url=http\%3A\%2F\%2Fsulawesi.cseas.kyotou.ac.jp\%2Flib\%2Fpdf\%2FGeorgeJunusAditjondro.pdf\&ei=5SOzUreMsG_rgemq4CgDA\&usg=AFQjCNEA1s3GFSaCekjinEVmIyjLiRv8EQ\&sig 2=y5IqXQGtXSJd2zGWOUC01A

Alvesson, M. \& Skoldberg, K. 2000. Reflexive Methodology: New Vistas for Qualitative Research. London: SAGE Publications.

Burrus, Jones, Sackley, Walker. 2013. It's the students, stupid: how perceptions of student reporting impact cheating. (online) http://www.thefreelibrary.com/It's+the+students, +stupid\%3A+how+perceptio ns+of+student+reporting...-a0332788552

Bond, Rod. Dan Smith, Peter H. 1996. Culture and conformity: a meta analysis of studies using asch's (1952b, 1956) Line Judgment Task.

http://www.radford.edu/ jaspelme/_private/gradsoc_articles/individualism_co llectivism/conformity\%20and\%20culture.pdf

Fitriana, F. (2019). Definisi Diri Dan Definisi Situasi Remaja Dalam Penjajakan Karier. Jurnal Mimbar: Media Intelektual Muslim Dan Bimbingan Rohani, 5(1), 16-25. https://doi.org/10.47435/mimbar.v5i1.74

Gouthro, David. What's courage got. ( online) http://www.banffcentre.ca/leadership/library/pdf/whats_courage_article.pdf 
Hakim, Zainuddi. 1992. Pangnganjak Tomatoa. Jakarta : Departeman Pendidikan dan Kebudayaan.

Heyns, and Pretorius. 2005. Fortitude as stress-resistance: development and validation of the fortitude Questionnaire (forq). (online)

http://www.monashuniversity.co.za/tyronepretorius/fortitude-questionnaire.pdf

Irianto, Kahar, Ludigdo, Triyuwono. 2013. Management Control Systems Concept Construction Of Pangngadereng Based On Local Wisdom Values. (online)

http://www.iosrjournals.org/iosr-jbm/papers/Vol8-issue2/C0822130.pdf

Lee, Guang _lee. 2013. Re-emphasizing character education in early childhood programs.(online)

http://www.thefreelibrary.com/Reemphasizing+character+education+in+early+childhood+programs\%3A...$\underline{\mathrm{a} 0345276663}$

Lickona, Thomas. 2012. Educating for Character: mendidik untuk membentuk karakter. Jakarta: Bumi Aksara

Marie L.; Kersey, Katharine C..2013. Connecting Children To Kindness. http://www.thefreelibrary.com/Connecting+children+to+kindness $\% 3 \mathrm{~A}+$ encou raging+a+culture+of+empathy.-a0338522430

Miller, Rielle. 2005. Moral Courage: Definition and Development. (online)

http://www.ethics.org/files/u5/Moral_Courage_Definition_and_Development. $\mathrm{pdf}$

Musbikin, I. (2016). Istanthiq Al-Qur'an (Pengenalan Studi Al-Qur'an Pendekatan Interdisipliner). Bandung: Pustaka Pelajar

Muslifar, R., Irawan, AW. (2020). Karakter Ideal Konseli dalam Praktek Kearifan Lokal Masyarakat Desa. Jurnal Bimbingan dan Konseling Borneo. Vol. 2 No. 1

Rokhman, wahibur. 2010. The Effect of Islamic Work Ethics on Work Outcomes. (online).http://ejbo.jyu.fi/pdf/ejbo_vol15_no1_pages_21-27.pdf

Sikki, Hakim, Mahmud, dan Sande. 1998. Nilai-nilai budaya dalam susastra Sulawesi Selatan. Jakarta: Departemen Pendidikan dan Kebudayaan. 


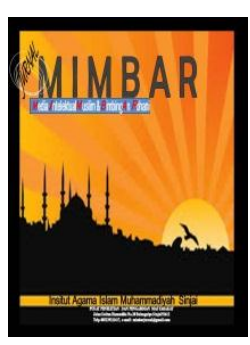

\section{MIMBAR}

Jurmal Media Intelektual Muslim dan Bimbingan Rohani

Volume 7, No. 1, 2021

ISSN (print) : 2442-3217

ISSN (online) : 2716-3806

Homepage : http://journal.iaimsinjai.ac.id/indeks.php/mimbar

Sikki, Rijal, Nasruddin, dan Syamsul Alam. 1998. Nilai dan Manfaat pappaseng dalam sastra Bugis. Jakarta: Departemen pendidikan dan Kebudayaan.

Sustein R, cass. Ullment_Margalit, Edna. 2001. Solidarity goods. (online) http://onlinelibrary.wiley.com/doi/10.1111/1467-9760.00121/abstract

Pelras, Cristian. 2006. Manusia Bugis. Jakarta : Nalar

Pusat Pembinaan dan pengembangan bahasa. 1981. Sastra Lisan Bugis. Jakarta: Departemen Pendidikan dan kebudayaan. 